\title{
Performance of the PneuX System: A Bench Study Comparison With 4 Other Endotracheal Tube Cuffs
}

\author{
Christopher T Chenelle, Taiga Itagaki MD, Daniel F Fisher MSc RRT, Lorenzo Berra MD, and \\ Robert M Kacmarek PhD RRT FAARC
}

\begin{abstract}
BACKGROUND: Cuff design affects microaspiration, a risk factor for pneumonia. We questioned whether the PneuX low-volume fold-free cuff design would prevent cuff leakage and maintain the same tracheal wall pressure as high-volume, low-pressure (HVLP) cuffs. METHODS: We evaluated 4 HVLP-cuffed endotracheal tubes (ETTs), Hi-Lo (polyvinyl chloride [PVC]), Microcuff (polyurethane [PU]), SealGuard (PU + tapered), and TaperGuard (PVC + tapered), and the PneuX with its dedicated tracheal seal monitor. In Part 1, we determined tracheal wall pressure using each cuff's capacity to support water columns across recommended intracuff pressures. In Part 2, we evaluated the tracheal seal monitor function at recommended settings. In Part 3, we compared leakage volumes of all ETTs during $30 \mathrm{~min}$ of simulated mechanical ventilation or during $8 \mathrm{~h}$ if no leak occurred. Parts 1 and 3 were performed with/without lubrication and PEEP. RESULTS: In Part 1, PneuX cuffs exerted an average tracheal wall pressure of $27.4 \pm 2.4 \mathrm{~cm} \mathrm{H}_{2} \mathrm{O}$ at the recommended intracuff pressure of approximately $80 \mathrm{~cm} \mathrm{H} \mathrm{H}_{2} \mathrm{O}$. Tracheal wall pressure did not differ among $\mathrm{HVLP}$ cuffs $\left(19.6 \pm 1.4\right.$ to $\left.29.5 \pm 1.4 \mathrm{~cm} \mathrm{H}_{2} \mathrm{O}\right)$. In Part 2, preinflation intracuff pressure affected the time to obtain tracheal seal monitor pressure attainment $(P<.01)$. The tracheal seal monitor generated average calculated tracheal wall pressure of $33.4 \pm 1.2 \mathrm{~cm} \mathrm{H}_{2} \mathrm{O}$. In Part 3, PneuX ETT showed no leak across $8 \mathrm{~h}$ for all trials. Overall, leakage volume was lower with PU $(P<.01)$ and PneuX $(P<.01)$ than with PVC cuffs, regardless of shape, and lower with lubrication and/or PEEP (all $P<.01)$. In each HVLP cuff, lubrication alone eliminated leak at an intracuff pressure of $\leq 30 \mathrm{~cm} \mathrm{H} \mathrm{H}_{2} \mathrm{O}$. CONCLUSIONS: The PneuX cuff generally exerted acceptable tracheal wall pressure, but the tracheal wall pressure monitor allowed pressures exceeding $30 \mathrm{~cm} \mathrm{H}_{2} \mathrm{O}$ in some trials and was the only ETT to prevent leak in all tests. For HVLP cuffs, leak was reduced by PU and PEEP and eliminated by lubrication. Key words: intubation; intratracheal; ventilator-associated pneumonia; respiratory aspiration. [Respir Care 2017;62(1):102-112. (C) 2017 Daedalus Enterprises]
\end{abstract}

\section{Introduction}

Microaspiration of contaminated secretions into the lower airway is a known risk factor of ventilator-associ-

\footnotetext{
Mr Chenelle, Mr Fisher, and Dr Kacmarek are affiliated with the Department of Respiratory Care, Massachusetts General Hospital, Boston, Massachusetts. Drs Itagaki, Berra, and Kacmarek are affiliated with the Department of Anesthesia, Critical Care, and Pain Medicine, Massachusetts General Hospital and Harvard Medical School, Boston, Massachusetts.

This study was financed in part by a grant from Venner Medical. Dr Kacmarek has disclosed relationships with Orange Medical, Covidien, and Venner Medical. Dr Berra has disclosed relationships with EndOclear LLC and Venner Medical. The other authors have disclosed no conflicts of interest.
}

ated pneumonia (VAP), ${ }^{1,2}$ a complication associated with substantial morbidity, mortality, and cost. ${ }^{3,4}$ Maintaining endotracheal tube (ETT) intracuff pressure between 20 and $30 \mathrm{~cm} \mathrm{H}_{2} \mathrm{O}$ is important for minimizing microaspira-

\footnotetext{
Dr Itagaki presented a version of this work at the AARC Congress, held December 9-11, 2014, in Las Vegas, Nevada.

Correspondence: Robert M Kacmarek PhD RRT FAARC, Respiratory Care Services, Department of Anesthesia, Critical Care and Pain Medicine, Massachusetts General Hospital and Harvard Medical School, Warren Building 1225, 55 Fruit Street, Boston, MA 02114. E-mail: rkacmarek@partners.org.
}

DOI: $10.4187 /$ respcare.04996 
tion and VAP and avoiding tracheal injury. ${ }^{1,2,5,6}$ Devices that continuously regulate intracuff pressure facilitate cuff pressure management ${ }^{7-9}$; however, other factors, including cuff design, also significantly affect secretion leakage. ${ }^{7,10-16}$

The primary mechanism of microaspiration is believed to be movement through longitudinal folds in the material of the inflated cuff. ${ }^{11,13,17-19}$ These folds are an unavoidable consequence of the physical characteristics of modern high-volume low-pressure (HVLP) cuffs, being effectively inelastic with a diameter exceeding that of the trachea. By design, the excess cuff material folds back over itself within the trachea, creating a network of channels that can allow for the silent aspiration of contaminated secretions. ${ }^{17-19}$

Efforts to decrease microaspiration have led to the introduction of new cuff materials and shapes aimed specifically at minimizing the effects of these folds. These modifications have consistently been shown in both bench and clinical studies to reduce but not eliminate fluid leakage past the cuff without additional preventive measures. ${ }^{11-13,20-22}$ Consequently, several fold-free cuff designs have been developed, producing promising results. . $^{13,23-26}$

One commercially available fold-free design is the lowvolume silicone cuff, the PneuX ETT (Venner Medical, Dänischenhagen, Germany). Preliminary bench and clinical studies have demonstrated impressive leak prevention without compromising the tracheal mucosa. ${ }^{27-32}$

The physical properties of the cuff material require a high intracuff pressure to create a seal, with roughly $50 \mathrm{~cm} \mathrm{H}_{2} \mathrm{O}$ needed just to overcome elasticity. ${ }^{31}$ The company recommends a target intracuff pressure of $80 \mathrm{~cm} \mathrm{H}_{2} \mathrm{O}$, which they equate to a tracheal wall pressure of $27.2 \mathrm{~cm} \mathrm{H}_{2} \mathrm{O} .{ }^{31}$ The PneuX ETT only functions with the tracheal seal monitor, a PneuX-specific automatic cuff pressure controller.

This study was designed to achieve the following goals: (1) to determine the tracheal wall pressure exerted by the PneuX system and compare it with the tracheal wall pressure exerted by polyvinyl chloride (PVC)- and polyurethane (PU)-based HVLP ETT cuffs; (2) to determine whether the PneuX tracheal seal monitor accurately maintains tracheal wall pressure in the recommended clinical range of 20-30 $\mathrm{cm} \mathrm{H}_{2} \mathrm{O}$; and (3) to determine and compare the abilities of 5 ETT cuffs to prevent fluid leakage in a model trachea. Although others have evaluated some of these issues, they have not been systematically assessed in a series of commonly recommended ETTs.

\section{Methods}

We evaluated 5 8-mm inner diameter ETT types with unique cuff designs (Fig. 1). The Hi-Lo (Mallinckrodt, Dublin, Ireland), Microcuff (Kimberly-Clark, Irving, Texas), TaperGuard (Mallinckrodt), and SealGuard (Mallinckrodt) ETTs use HVLP cuffs with different com-

\section{QUICK LOOK}

\section{Current knowledge}

The design of commonly used endotracheal tubes (ETT) does not prevent aspiration of fluid past their inflated cuffs. However, newly designed ETTs may provide better sealing of the airway. However, the use of a lubricant seems to prevent leakage past all ETT cuffs.

\section{What this paper contributes to our knowledge}

This bench study establishes that in experimental conditions, the PneuX ETT provided better sealing of the airway than that of standard ETTs despite the high required airway inflating pressure. However, the tracheal wall pressure may exceed $30 \mathrm{~cm} \mathrm{H}_{2} \mathrm{O}$ by 3-4 $\mathrm{cm} \mathrm{H}_{2} \mathrm{O}$. In addition, the use of a lubricant over any ETT cuff seemed to prevent leakage of fluid past the cuff.

binations of material (PVC/PU) and shape (tapered/nontapered). The PneuX ETT uses a high-elasticity, low-volume silicone cuff.

The PneuX-specific cuff controller (tracheal seal monitor) was also evaluated. To operate the tracheal seal monitor, users select a seal pressure, representing tracheal wall pressure, of 13.6, 27.2, 40.8, 54.4, or $68.0 \mathrm{~cm} \mathrm{H}_{2} \mathrm{O}$.

All 3 parts of the study were performed with the tracheal model positioned vertically $90^{\circ}$ from supine. This is the worst-case scenario for potential leakage of fluid past the ETT cuff. However, this position is consistent with that used in other bench studies, and in the ICU, most patients are maintained at a $\geq 30^{\circ}$ head-up position.

\section{Part 1: Tracheal Wall Pressure}

We determined the pressure exerted by the various cuffs against a simulated tracheal wall with the HVLP cuffs at an intracuff pressure of $25 \mathrm{~cm} \mathrm{H}_{2} \mathrm{O}$ and the PneuX at its recommended intracuff pressure of $80 \mathrm{~cm} \mathrm{H}_{2} \mathrm{O}$. An intracuff pressure of $25 \mathrm{~cm} \mathrm{H}_{2} \mathrm{O}$ was chosen because it is in the clinically acceptable cuff pressure range $e^{1,2,5}$ and in the range of tracheal wall pressure that the PneuX indicates would be established by an intracuff pressure of $80 \mathrm{~cm} \mathrm{H}_{2} \mathrm{O}$. Figure 2A shows the experimental setup for this part of the study. Tracheal wall pressure was determined by inserting the ETT into a tracheal model, ${ }^{17,31}$ with a tapered extension, clamped in a vertical position. The ETT pilot balloon was connected to a 3-way stopcock with one port used to adjust intracuff pressure and the other connected to a pressure transducer (Edwards Life Sciences, Irvine, Califor- 


\section{Performance of Endotracheal Tube Cuffs}

\begin{tabular}{|c|c|c|c|c|c|}
\hline Type: & Hi-Lo & Microcuff & SealGuard & TaperGuard & PneuX \\
\hline \multirow[t]{2}{*}{ Company: } & Mallinckrodt & $\begin{array}{l}\text { Kimberly- } \\
\text { Clark }\end{array}$ & Mallinckrodt & Mallinckrodt & $\begin{array}{l}\text { Venner } \\
\text { Medical }\end{array}$ \\
\hline & Dublin, Ireland & Irving, TX & Dublin, Ireland & Dublin, Ireland & $\begin{array}{c}\text { Dänischenhagen, } \\
\text { Germany }\end{array}$ \\
\hline Cuff type: & \multicolumn{4}{|c|}{ High-volume low-pressure (HVLP) } & Low-volume \\
\hline Shape: & Spheroid & Cylindrical & Tapered & Tapered & Spheroid \\
\hline Material: & PVC & PU & PU & PVC & Silicone \\
\hline Elasticity: & \multicolumn{4}{|c|}{ Low } & High \\
\hline Target IP: & \multicolumn{4}{|c|}{$25 \mathrm{~cm} \mathrm{H}_{2} \mathrm{O}$} & $80 \mathrm{~cm} \mathrm{H}_{2} \mathrm{O}$ \\
\hline
\end{tabular}

Fig. 1. Characteristics of the 5 tested endotracheal tube cuffs. Three cuffs of each type were used in each part of the study. PVC $=$ polyvinyl chloride, PU = polyurethane, Target IP = suggested intracuff pressure. Cuff type is based on company classification.

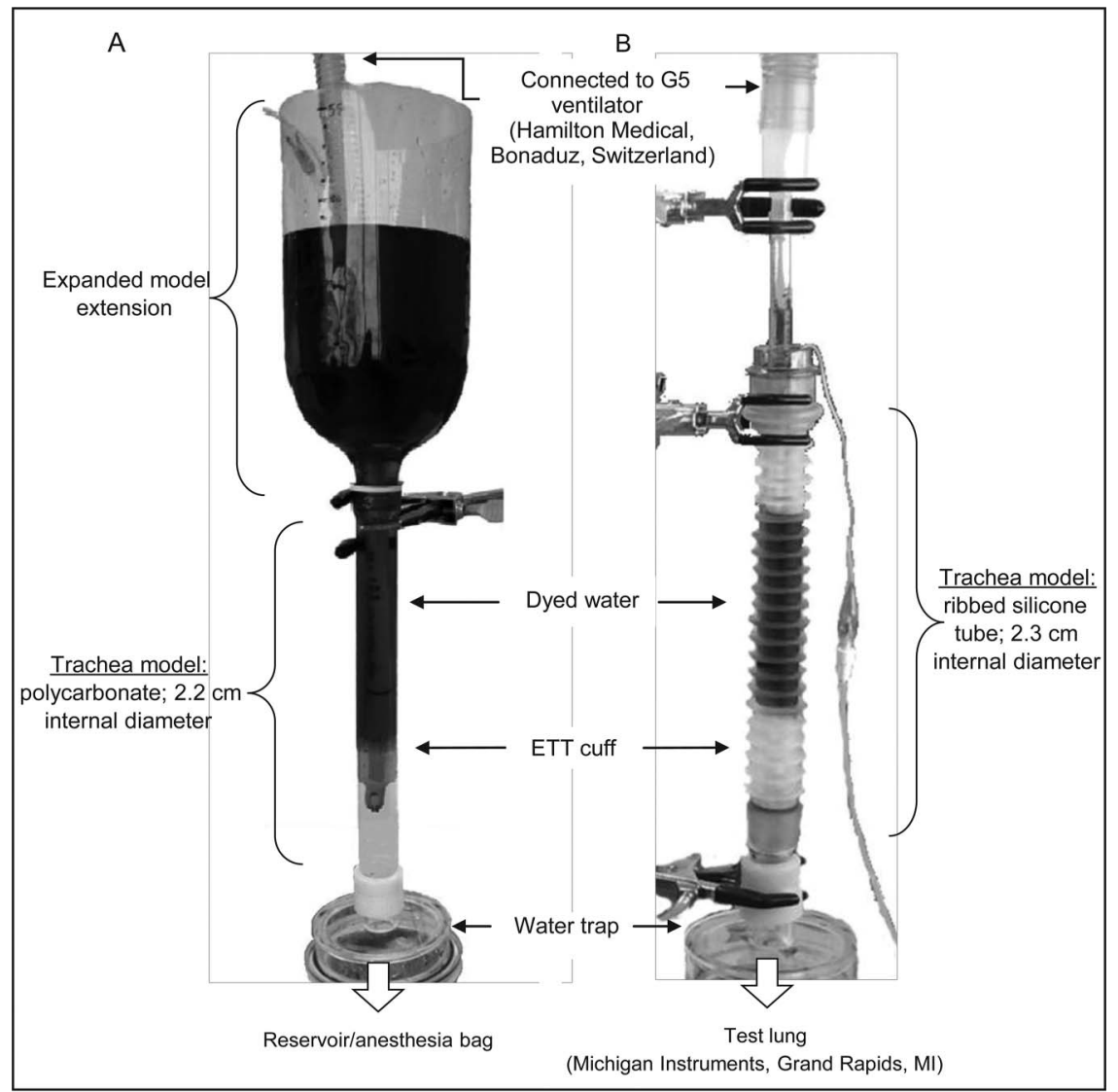

Fig. 2. Experimental setups for Part 1 (tracheal wall pressure) and Part 3 (leakage past the endotracheal tube cuff). A: The trachea model used in Part 1 to determine tracheal wall pressure. Tests were performed at heights of dyed water of 20, 25, 30, 35, and 40 cm. B: the setup used in Part 3 to compare fluid leakage by the endotracheal tube cuff. Leakage volume was determined from the change in height of a column of $35 \mathrm{~mL}$ of dyed water over 30 min during lung model mechanical ventilation (B).

nia) and analog-digital converter (DataQ Logger, model DI-718B-U, DATAQ Instruments, Akron, Ohio) for continuous recording of the intracuff pressure by WINDAQ software (DATAQ Instruments, Akron, Ohio). Before each test, the pressure transducers were calibrated using a 2-point method with a National Institute of Standards and Tech- 
nology pressure calibrator (Fisher Scientific, Pittsburgh, Pennsylvania).

Once in place, the ETT cuff was inflated to $20 \mathrm{~cm} \mathrm{H}_{2} \mathrm{O}$ above its target pressure: $45 \mathrm{~cm} \mathrm{H}_{2} \mathrm{O}$ for HVLP cuffs, $100 \mathrm{~cm} \mathrm{H}_{2} \mathrm{O}$ for the PneuX. A dyed-water column of height $20,25,30,35$, or $40 \mathrm{~cm}$, performed in randomized order, was then established above the cuff. Intracuff pressure was then gradually decreased with a syringe while another investigator, blinded to the intracuff pressure, monitored for flow leakage past the cuff. This was defined as fluid flowing between the cuff and the tracheal wall, as opposed to passage through folds in cuff material, which could be visualized. If the height of the water column visibly changed due to passage of fluid through folds before flow leakage was seen, the trial was stopped and repeated.

Once flow leakage was observed, a timestamp was immediately recorded in WinDaq, used to retrospectively determine the exact corresponding intracuff pressure. This intracuff pressure signaled equality of the tracheal wall pressure and water column height. This was repeated for all 5 water heights, with/without CPAP $\left(10 \mathrm{~cm} \mathrm{H}_{2} \mathrm{O}\right.$ applied with the Hamilton G5 ventilator [Reno, Nevada]) and with/without cuff lubrication, for each ETT (20 runs/ETT). Cuff lubrication procedure consisted of applying a thin layer of water-soluble jelly (MediChoice, Owens \& Minor, Mechanicsville, Virginia) to the inflated cuff and then deflation and ETT insertion. Three new ETTs of each type were evaluated.

The effects of CPAP, lubrication, cuff design, and cuff group (HVLP vs PneuX cuffs) on tracheal wall pressure were considered. The correlation between water column height (ie, tracheal wall pressure) and intracuff pressure at flow leakage was determined for each group.

\section{Part 2: Tracheal Seal Monitors}

The PneuX system manual instructs users to pre-inflate the cuff to an initial intracuff pressure (pre-intracuff pressure) of $80 \mathrm{~cm} \mathrm{H}_{2} \mathrm{O}$ before connecting the tracheal seal monitor. We tested pre-intracuff pressures of $0,70,80$, and $90 \mathrm{~cm} \mathrm{H}_{2} \mathrm{O}$, with the tracheal seal monitor at a seal pressure of $27.2 \mathrm{~cm} \mathrm{H}_{2} \mathrm{O}$ for all trials. The model trachea, pilot balloon connections, data logging, and calibration technique were the same as in Part 1. For each trial, with intracuff pressure continuously recorded, a PneuX ETT was inserted, and the cuff was manually inflated to the desired pre-intracuff pressure. This stopcock port was closed, and the tracheal seal monitor was connected, powered on, and set to a seal pressure of $27.2 \mathrm{~cm} \mathrm{H}_{2} \mathrm{O}$. The port was then reopened, and a timestamp was entered in WINDAQ to mark the start time $(t=0)$.

The system was monitored until the tracheal seal monitor indicated seal pressure attainment (SP attained), at which point another timestamp was entered. Recording was then continued for $5 \mathrm{~min}$. Three new tracheal seal monitors were evaluated using the 3 PneuX ETTs from Part 1. All combinations of tracheal seal monitor, ETT, and preintracuff pressure were included (12 runs/tracheal seal monitor). The time (from $t=0$ ) to SP attained was determined retrospectively for each run, and the effects of tracheal seal monitor, ETT, and pre-intracuff pressure were considered.

The intracuff pressures recorded after SP attained were averaged over 1-min intervals and the 4-5-min interval used for analysis of tracheal seal monitor-generated intracuff pressure. The effects of the tracheal seal monitor, ETT, and pre-intracuff pressure were considered.

\section{Part 3: Static Leak Test}

The leak prevention of the 5 ETT types was compared using the setup shown in Figure 2 (right)..$^{9,11}$ For the HVLPcuffed ETT, intracuff pressure was controlled at 20, 25, and $30 \mathrm{~cm} \mathrm{H}_{2} \mathrm{O}$ using a cuff pressure controller (Intellicuff, Hamilton Medical G5 ventilator, Reno, Nevada) that we previously evaluated. ${ }^{9}$ For the PneuX, intracuff pressure was controlled by the tracheal seal monitor at a seal pressure of $27.2 \mathrm{~cm} \mathrm{H}_{2} \mathrm{O}$.

After the ETT was inserted into the tracheal model, the cuff was inflated to the target intracuff pressure and maintained with the IntelliCuff or tracheal seal monitor. Using CPAP of $10 \mathrm{~cm} \mathrm{H}_{2} \mathrm{O}$ to suppress immediate leak, $35 \mathrm{~mL}$ of dyed water was added, and then the height of the fluid column above the cuff was measured. Mechanical ventilation was performed for $30 \mathrm{~min}$ as follows: pressure assist-control mode, frequency 20 breaths/min, pressure control $15 \mathrm{~cm} \mathrm{H}_{2} \mathrm{O}$, inspiratory time $1 \mathrm{~s}$, and PEEP 0 or $10 \mathrm{~cm} \mathrm{H}_{2} \mathrm{O}$. The change in column height was determined to compute total leakage volume, using the inner diameter of the tracheal model and outer diameter of the ETT and calculating as a system of concentric cylinders. If no change in height occurred after $30 \mathrm{~min}$, then the run was continued for $8 \mathrm{~h}$.

As in Part 1, this was repeated with and without PEEP $\left(10 \mathrm{~cm} \mathrm{H}_{2} \mathrm{O}\right)$ and with and without cuff lubrication for each ETT. The cuff lubrication procedure was the same as in Part 1. Three new ETTs of each type were evaluated, and results were averaged. Intracuff pressure was trailed in ascending order until no leak was seen for $30 \mathrm{~min}$. The effects of PEEP, lubrication, intracuff pressure, and cuff type on fluid leakage were considered.

\section{Statistical Analysis}

We powered all comparison to $\geq 0.8$ with a difference of $1 \mathrm{SD}$ and a significance of $<.05$. In Part 1 , a total of 300 trials were performed (required trials: 250); in Part 2, 36 trials were performed (required trials: 28); and in Part 3, 204 trials were performed (required trials: 76). All statis- 

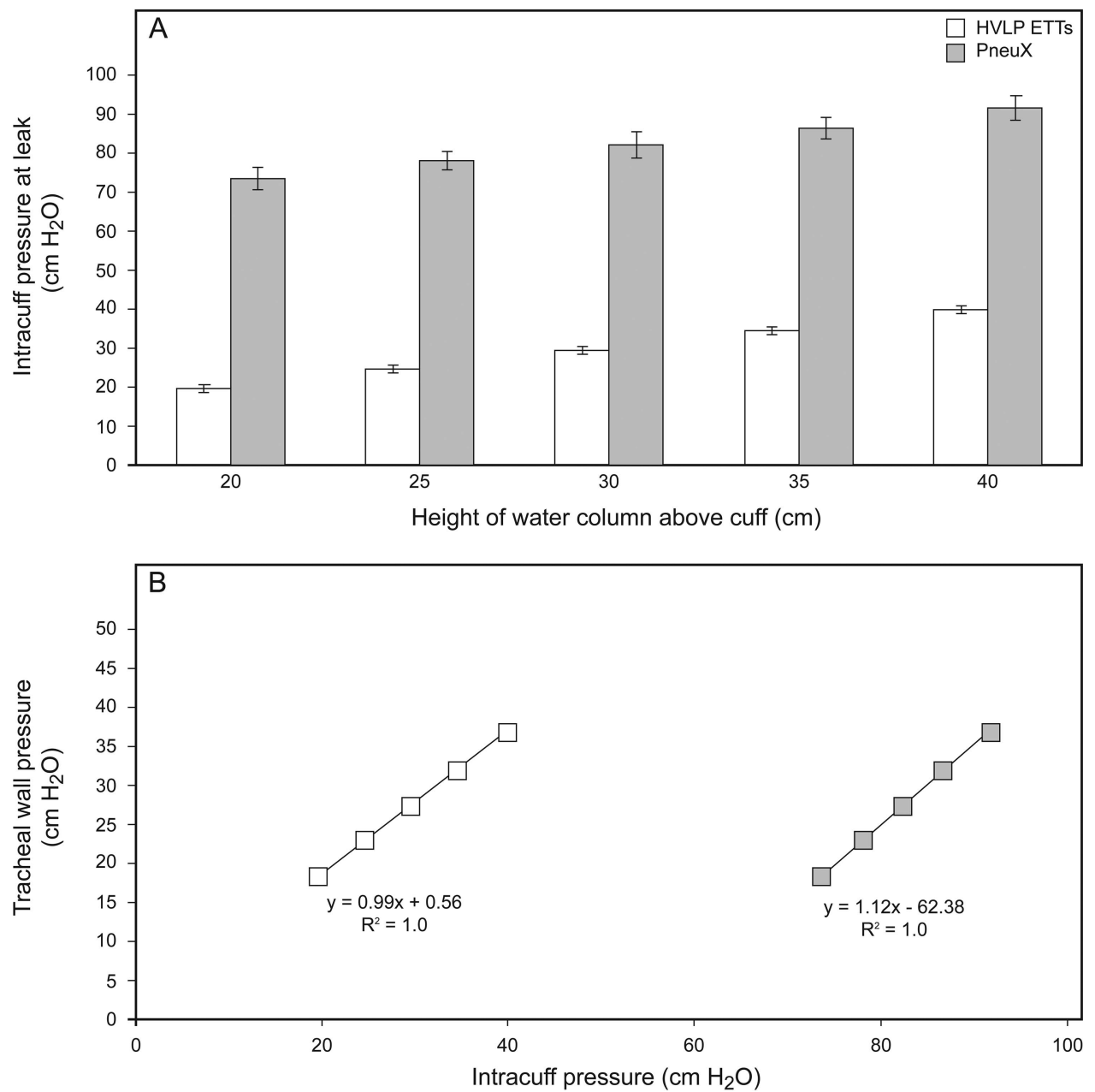

Fig. 3. Intracuff pressure versus tracheal wall pressure of high-volume low-pressure (HVLP) and PneuX cuffs. HVLP-cuffed endotracheal tubes (ETTs) included Hi-Lo, Microcuff, SealGuard, and TaperGuard (3 ETTs each) over 4 PEEP/lubrication conditions and PneuX (3 ETTs) over 4 PEEP/lubrication conditions. A: Bars represent the mean \pm SD at which flow leakage began at that water column height; at this intracuff pressure, the hydrostatic pressure of the water column is equivalent to tracheal wall pressure. Shown are the correlations between these intracuff pressures at flow leakage and tracheal wall pressures for each ETT cuff group (B).

tical testing was performed using R-based statistical software (R, version 3.1.2, R Project for Statistical Computing, Vienna, Austria). Data normality was determined using the Shapiro-Wilk test. For parametric data, $t$ tests or univariate/multivariate analysis of variance, as appropriate, were used, with Tukey's honest significant difference test for post hoc analysis. For nonparametric data, Wilcoxon rank-sum and Kruskal-Wallis tests were used. A $P$ value of $<.05$ was used to indicate statistical significance.

\section{Results}

\section{Part 1: Tracheal Wall Pressure}

The average recorded intracuff pressure at flow leakage for each water column height is shown in Figure 3A. Neither CPAP, lubrication, nor CPAP with lubrication af- fected tracheal wall pressure, so the results from these conditions were combined. Additionally, no differences were seen between HVLP-cuffed ETT types; thus, these results are considered as a single group. Figure 3B shows the correlations between intracuff pressure at flow leakage and tracheal wall pressure (ie, water column height) for HVLP-cuffed ETT and PneuXETT, using the means shown in Figure 3A. For HVLP cuffs, tracheal wall pressures of $20-30 \mathrm{~cm} \mathrm{H}_{2} \mathrm{O}$ were exerted by an intracuff pressure of $19.6 \pm 1.4$ to $29.5 \pm 1.4 \mathrm{~cm} \mathrm{H}_{2} \mathrm{O}$ (no. = 48). Specifically, the intracuff pressure for the Hi-Lo varied from $18.0 \pm 5.5$ to $27.0 \pm 8.2 \mathrm{~cm} \mathrm{H}_{2} \mathrm{O}$, for the Microcuff from $19.0 \pm 5.8$ to $27.5 \pm 8.3 \mathrm{~cm} \mathrm{H}_{2} \mathrm{O}$, for the SealGuard from $17.5 \pm 5.4$ to $26.7 \pm 8.2 \mathrm{~cm} \mathrm{H}_{2} \mathrm{O}$, and for the TaperGuard from $19.6 \pm 1.8$ to $27.5 \pm 8.4 \mathrm{~cm} \mathrm{H}_{2} \mathrm{O}$. Leakage occurred in HVLP cuffs when the column height equaled the intracuff pressure. For the PneuX, tracheal wall pressures of $20-30 \mathrm{~cm} \mathrm{H}_{2} \mathrm{O}$ 

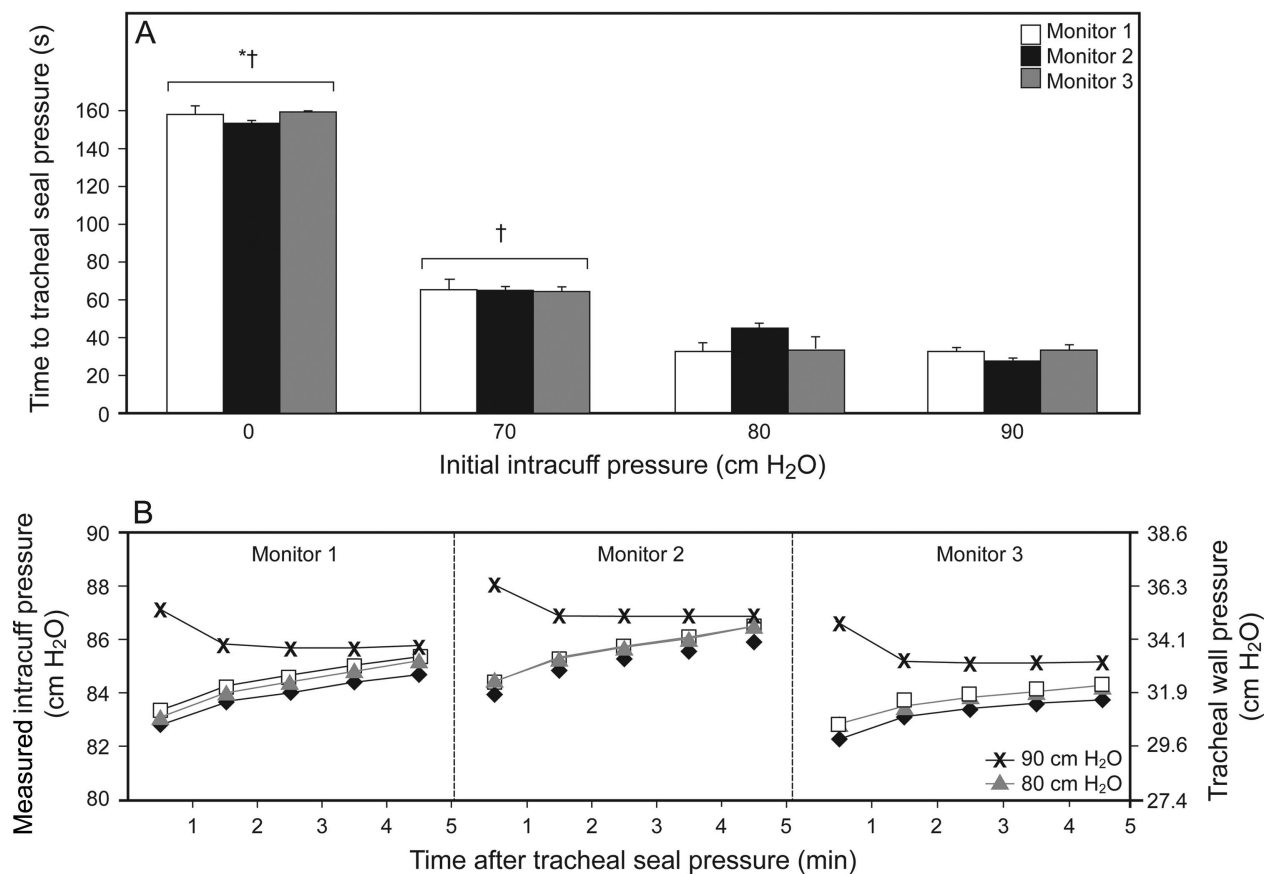

Fig. 4. Comparison of tracheal seal monitors. A: Time to attain tracheal seal pressure at the $27.2 \mathrm{~cm} \mathrm{H}_{2} \mathrm{O}$ setting for each tracheal seal monitor at different initial intracuff pressure. Bars show mean \pm SD of 3 PneuX endotracheal tubes. B: Intracuff pressure measured after tracheal seal pressure attained, averaged across 1-min intervals at different initial intracuff pressures. The associated tracheal wall pressures use the PneuX correlation in Figure 3B, $y=1.1218 \mathrm{x}-62.377 .{ }^{*} P<.05$ versus initial intracuff pressures of 70,80 , and 90 $\mathrm{cm} \mathrm{H}_{2} \mathrm{O}$; $P<.05$ versus initial intracuff pressures of 80 and $90 \mathrm{~cm} \mathrm{H}_{2} \mathrm{O}$.

were exerted by intracuff pressure of $73.5 \pm 2.9$ to $82.1 \pm 3.4 \mathrm{~cm} \mathrm{H}_{2} \mathrm{O}$ (no. $=12$ ). The PneuX cuffs exerted an average tracheal wall pressure of $27.4 \pm 2.4 \mathrm{~cm} \mathrm{H}_{2} \mathrm{O}$ at an intracuff pressure of $80 \mathrm{~cm} \mathrm{H}_{2} \mathrm{O}$. No significant difference existed between the 3 PneuX ETTs $(P=.056$, analysis of variance).

\section{Part 2: Tracheal Seal Monitors}

The tracheal seal monitor results are shown in Figure 4. Figure 4A shows the times to SP attained of the tracheal seal monitor. Times were shorter with pre-intracuff pressure of 70,80 , and $90 \mathrm{~cm} \mathrm{H}_{2} \mathrm{O}$ than with $0 \mathrm{~cm} \mathrm{H}_{2} \mathrm{O}$ for all tracheal seal monitors and ETTs $(P<.01)$. Additionally, times with pre-intracuff pressures of 80 and $90 \mathrm{~cm} \mathrm{H}_{2} \mathrm{O}$ were shorter than with $70 \mathrm{~cm} \mathrm{H}_{2} \mathrm{O}(P<.01)$. There was no difference in times between pre-intracuff pressure of 80 and $90 \mathrm{~cm} \mathrm{H}_{2} \mathrm{O}$. Figure 4B shows the measured intracuff pressure (and average tracheal wall pressure determined in Part 1) for each tracheal seal monitor and pre-intracuff pressure, 5 min after SP attained.

The overall averages of recorded intracuff pressure during the 4-5-min interval for each tracheal seal monitor were $85.2 \pm 0.4,86.4 \pm 0.4$, and $84.4 \pm 0.6 \mathrm{~cm} \mathrm{H}_{2} \mathrm{O}$. Using the Part 1 results, this corresponds to an average tracheal wall pressure of $33.2,34.6$, and $32.3 \mathrm{~cm} \mathrm{H}_{2} \mathrm{O}$, respectively. There was no difference between the 3 ETTs tested $(P=.27$, analysis of variance).

\section{Part 3: Static Leak Test}

In all cases with no leak at $30 \mathrm{~min}$, there was also no leak at $8 \mathrm{~h}$. All non-zero leakage volumes are for $30 \mathrm{~min}$. Figure 5 shows the leakage volumes of each ETT type, intracuff pressure, and condition. At a seal pressure of $27.2 \mathrm{~cm} \mathrm{H}_{2} \mathrm{O}$, PneuX ETT showed no leak across all conditions, the only ETT type to do so. HVLP cuffs were compared against the PneuX and other HVLP cuffs for the same intracuff pressure.

Overall, leakage volume was lower with PU $(P<.01)$ and PneuX $(P<.01)$ than PVC cuffs, with no difference between PneuX and PU cuffs $(P=.79)$. No difference was seen between tapered and non-tapered HVLP cuffs $(P=.34)$. Leakage volume was significantly lower with lubrication and/or PEEP than with neither (all $P<.01$ ), but no differences existed between lubrication alone, PEEP alone, and both together. In each HVLP cuff, lubrication alone eliminated leak at an intracuff pressure $\leq 30 \mathrm{~cm} \mathrm{H}_{2} \mathrm{O}$.

Without lubrication or PEEP (Fig. 5A), the PneuX was the only ETT to show no leak; this differed from the Hi-Lo (all $P<.01$ ) and TaperGuard (all $P<.05$ ) at all intracuff pressures and the Microcuff $(P=.033)$ and SealGuard 

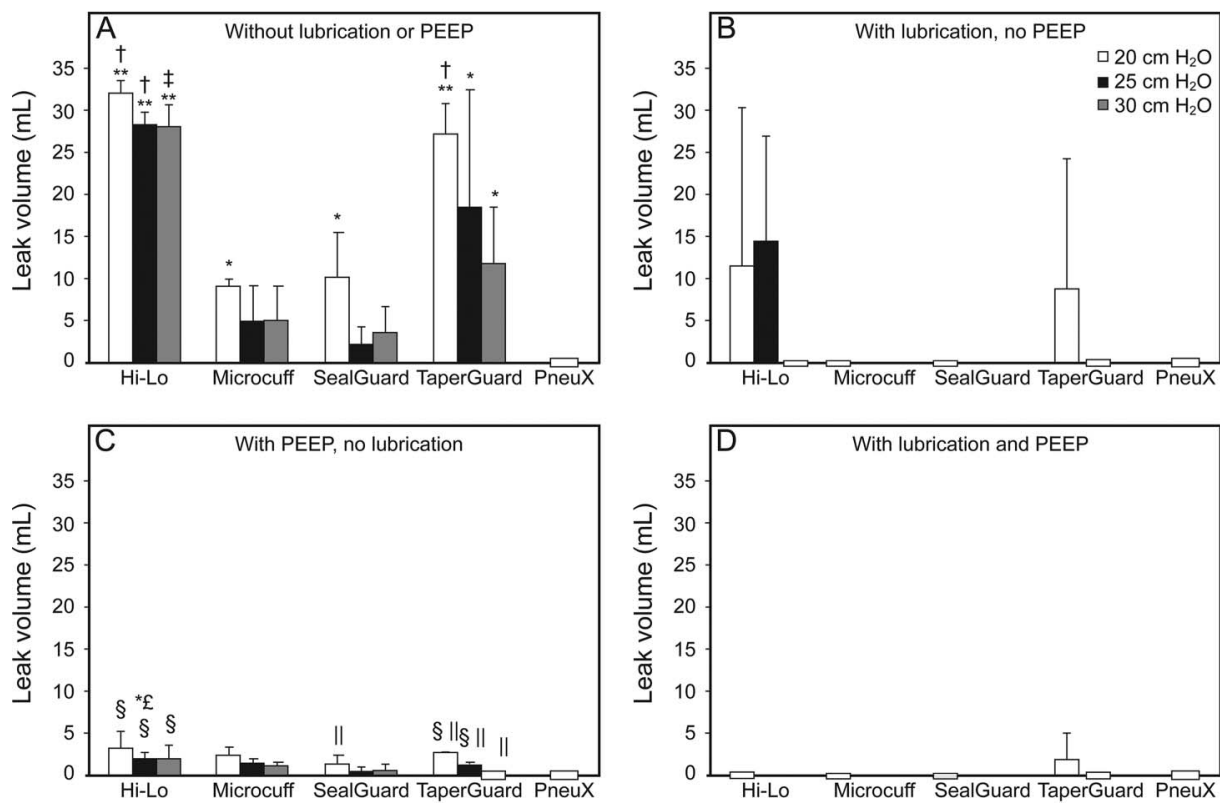

Fig. 5. Volume of leakage past the cuff over $30 \mathrm{~min}$ of mechanical ventilation. The intracuff pressure of the Hi-Lo, Microcuff, SealGuard, and TaperGuard ETTs were controlled by the IntelliCuff option on the Hamilton G5 ventilator; the PneuX tracheal tube cuff pressures were controlled by the tracheal seal monitor. A-D correspond to conditions with and without PEEP of $10 \mathrm{~cm} \mathrm{H}_{2} \mathrm{O}$ and lubrication. Bars represent mean \pm SD of 3 ETTs of each type, unless otherwise noted. ${ }^{*} P<.05$ versus PneuX; ${ }^{\star *} P<.01$ versus PneuX; $\dagger P<.05$ versus Microcuff and SealGuard at the same intracuff pressure; $\ddagger P<.01$ versus Microcuff, SealGuard, and TaperGuard at the same intracuff pressure; $£ P<.05$ versus SealGuard at the same intracuff pressure. $\S=$ water bubbled (but not ejected) for $\geq 1 \mathrm{ETT}$, indicating an incomplete seal. $\|=$ water ejected in $\geq 1 \mathrm{ETT}$, so data could not be recorded. Single white dash at the baseline indicates no leak after $30 \mathrm{~min}$, so the trial was continued to $8 \mathrm{~h}$; in all such scenarios, no leak was seen after $8 \mathrm{~h}$. In $\mathrm{C}$, the TaperGuard at intracuff pressure of $30 \mathrm{~cm} \mathrm{H}_{2} \mathrm{O}$ showed no leak in $2 \mathrm{ETT}$ and water ejection in $1 \mathrm{ETT}$.

$(P=.01)$ at intracuff pressure of $20 \mathrm{~cm} \mathrm{H}_{2} \mathrm{O}$. The Hi-Lo leaked more than the Microcuff (all $P<.05$ ) and SealGuard (all $P<.01$ ) at all intracuff pressures, the TaperGuard at intracuff pressure of $30 \mathrm{~cm} \mathrm{H}_{2} \mathrm{O}(P<.01)$, and the PneuX (all $P<.01$ ).

With lubrication but no PEEP (Fig. 5B), zero leakage was observed with the PneuX and with each of the HVLP cuffs at one of the tested intracuff pressures: the Microcuff and SealGuard at intracuff pressure of $20 \mathrm{~cm} \mathrm{H}_{2} \mathrm{O}$, the TaperGuard at $25 \mathrm{~cm} \mathrm{H}_{2} \mathrm{O}$, and the $\mathrm{Hi}-\mathrm{Lo}$ at $30 \mathrm{~cm} \mathrm{H}_{2} \mathrm{O}$. No significant differences existed between ETT types, although at intracuff pressure of $25 \mathrm{~cm} \mathrm{H}_{2} \mathrm{O}$, the difference between the Hi-Lo and the other ETT types was $P=.069$.

Results with PEEP but no lubrication are shown in Figure $5 \mathrm{C}$. Bubbling from positive pressure, indicating incomplete sealing, occurred in all Hi-Lo trials and at least one trial with both the SealGuard and TaperGuard. The PneuX was the only ETT type without any leakage or incomplete sealing observed. No significant differences existed between ETT types. With both PEEP and lubrication (Fig. 5D), zero leakage was observed with the PneuX and with each of the HVLP cuffs at one of the tested intracuff pressures: the Hi-Lo, Microcuff, and SealGuard at intracuff pressure of $20 \mathrm{~cm} \mathrm{H}_{2} \mathrm{O}$ and the TaperGuard at $25 \mathrm{~cm} \mathrm{H}_{2} \mathrm{O}$. No significant differences existed between ETT types. Comparing ETT types across conditions, the
Microcuff, SealGuard, and PneuX each demonstrated lower leakage volume than the Hi-Lo (all $P<.01$ ). No other significant differences were found.

\section{Discussion}

The major findings from this study are summarized as follows: (1) the low-volume silicone PneuX cuff averaged tracheal wall pressure within $20-30 \mathrm{~cm} \mathrm{H}_{2} \mathrm{O}$ at its recommended intracuff pressure of $80 \mathrm{~cm} \mathrm{H}_{2} \mathrm{O}$ and (2) the intracuff pressure generated by the tracheal seal monitor at a seal pressure of $27.2 \mathrm{~cm} \mathrm{H}_{2} \mathrm{O}$ were inconsistent with the target pressure, creating a tracheal wall pressure of 29.2$35.4 \mathrm{~cm} \mathrm{H}_{2} \mathrm{O}$; (3) at its recommended settings, the PneuX was the only ETT to completely prevent fluid leakage for $8 \mathrm{~h}$ in all tests; (4) for HVLP cuffs, PU cuffs outperformed PVC cuffs in leak prevention, regardless of shape; (5) the addition of PEEP markedly reduced the amount of leak past all ETT cuffs; (6) for all HVLP cuffs, adding lubrication alone prevented leak for $8 \mathrm{~h}$ at an intracuff pressure $\leq 30 \mathrm{~cm} \mathrm{H}_{2} \mathrm{O}$.

\section{Tracheal Wall Pressure}

Our tracheal wall pressure findings for the PneuX System are consistent with previous studies. ${ }^{23,31}$ Doyle et al ${ }^{31}$ 


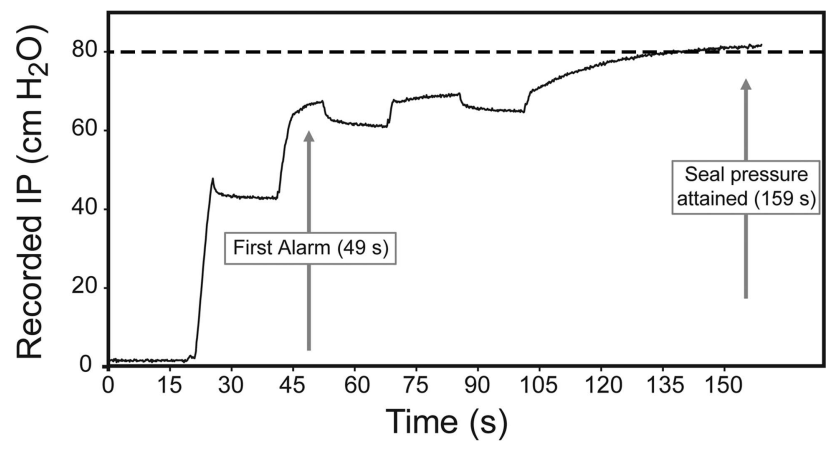

Fig. 6. Representative intracuff pressure (IP) waveform of a PneuX endotracheal tube cuff attached to a tracheal pressure monitor with no pre-inflation pressure. Time $=0$ represents the start of the run, when the tracheal seal monitor initiation was complete and tracheal seal pressure of $27.2 \mathrm{~cm} \mathrm{H}_{2} \mathrm{O}$ was set. The arrows show (1) the time of the first alarm (the leak signal) and (2) the time of seal pressure attained. The dashed line shows the target intracuff pressure of $80 \mathrm{~cm} \mathrm{H}_{2} \mathrm{O}$ for the PneuX endotracheal tube cuff.

measured tracheal wall pressure of PneuX and HVLP cuffs using bench, clinical, and radiological methods. Overall, they reported that tracheal wall pressure of the PneuX cuff ranged between 25 and $35 \mathrm{~cm} \mathrm{H}_{2} \mathrm{O}$, consistent with our results.

Our finding that intracuff pressure is strongly predictive of tracheal wall pressure in HVLP cuffs is consistent with existing literature. ${ }^{33,34} \mathrm{We}$ found that this property is unaffected by cuff design, lubrication, or PEEP. In contrast, a bench study by Li Bassi et $\mathrm{al}^{35}$ that used intracranial pressure sensors along the tracheal wall found significantly different and heterogeneously distributed tracheal wall pressure with different HVLP cuffs; cuff outer diameter was associated with likelihood of exerting high tracheal wall pressure.

\section{Tracheal Seal Monitors}

There has been significant progress made in electronic cuff pressure controllers, ${ }^{6-8}$ but functional variability and shortcomings in some such devices indicate that proper and safe performance cannot be assumed. ${ }^{36}$ Our findings (Fig. 4) reveal possible concerns with the tracheal seal monitor. Whereas the adjustment times (Fig. 4A) seen with sufficient pre-inflation may be inconsequential because the airway probably remains sealed, the higher times observed with lower or no pre-inflation could result in dangerous durations with an unsealed airway. Figure 6 shows the recorded intracuff pressure during a trial with no pre-inflation; neither immediate alarms nor rapid compensation occurred in such trials. Although airway sealing was not recorded, Venner Medical's estimation of $50 \mathrm{~cm} \mathrm{H}_{2} \mathrm{O}$ needed to overcome cuff elasticity ${ }^{31}$ suggests that nearly $50 \mathrm{~s}$ may have passed without a seal or alarm. Backup safety mechanisms should be added to tracheal seal monitors to address this phenomenon. That said, the tracheal seal monitor is not designed as an inflation device, solely to be used for pressure maintenance, according to the manufacturer.

Our assessment of the accuracy of 3 tracheal seal monitors revealed consistent overpressurization of the PneuX cuffs, with intracuff pressure converging above $80 \mathrm{~cm} \mathrm{H}_{2} \mathrm{O}$ in all scenarios (Fig. 4B). The average intracuff pressure recorded equates to tracheal wall pressure above both the $27.2 \mathrm{~cm} \mathrm{H}_{2} \mathrm{O}$ seal pressure tested and the accepted $30 \mathrm{~cm} \mathrm{H}_{2} \mathrm{O}$ threshold, although this is within the realm of what may be seen clinically with manual inflation. ${ }^{37}$ The clinical importance of this disparity requires additional investigation. Follow-up studies of the tracheal seal monitor, as done on other cuff pressure controllers, 7,16 are needed.

\section{Static Leak Test}

Assessment of leakage volume past the cuff under various conditions revealed that, at a seal pressure of $27.2 \mathrm{~cm} \mathrm{H}_{2} \mathrm{O}$, the PneuX cuff created a fold-free seal that prevented leak in all PEEP/lubrication scenarios, the only ETT to do so. This finding is consistent with existing literature on the PneuX system and other fold-free cuff designs. ${ }^{27,29}$

The PneuX cuff has repeatedly shown complete leak prevention in bench and clinical studies. ${ }^{27,29}$ It is important to note that there are other new style ETT cuffs, some also made of silicone, that may provide the same benefits as the PneuX tube.

The bench results from this study are consistent with our findings: Without PEEP or lubrication, all HVLP cuffs showed some fluid leakage at all intracuff pressures, whereas the PneuX showed no leak at the recommended settings. In this test condition, the PneuX outperformed PVC cuffs (Hi-Lo and TaperGuard) at all intracuff pressures and PU cuffs (Microcuff and SealGuard) at an intracuff pressure of $20 \mathrm{~cm} \mathrm{H}_{2} \mathrm{O}$. The lack of statistical significance with the PU cuffs at other intracuff pressures was a result of their performance. As indicated in Figure 5, a very small amount of leak occurred with the PU cuffs at 25 and $30 \mathrm{~cm} \mathrm{H}_{2} \mathrm{O}$ intracuff pressure.

Importantly, other fold-free prototype cuff designs have also demonstrated complete leak prevention in similar studies, which supports the concept's efficacy. Zanella et al ${ }^{13}$ created a prototype cuff by coating a Hi-Lo cuff with surgical gel and then wrapping it with a thin layer of high-compliance guayule latex to create a smooth outer surface, whereas Kolobow et $\mathrm{al}^{26}$ designed a prototype Lycra (spandex) cuff. Notably, both functioned at the intracuff pressure used for HVLP cuffs $\left(20-30 \mathrm{~cm} \mathrm{H}_{2} \mathrm{O}\right)$ and showed zero fluid leakage in bench studies.

For the HVLP cuffs, our findings suggest that PU cuffs are more effective than PVC cuffs at preventing leak, with no effect of cuff shape. Studies comparing HVLP cuffs have consistently found that PU cuffs outperform PVC 
cuffs. ${ }^{11,13,21,26}$ The effect of a tapered cuff is less clear from the existing literature. We found no advantage of a tapered shape in PU or PVC cuffs. Zanella et al ${ }^{13}$ found improved performance with tapered PVC but not PU cuffs, and Dave et $\mathrm{al}^{21}$ found improved leak prevention with tapered PU cuffs but only in larger trachea models. Pitts et $\mathrm{al}^{11}$ found similar performance between tapered and non-tapered PU cuffs. In a bench study by Li Bassi et al ${ }^{35}$ using artificial secretions and a tracheal model $30^{\circ}$ above horizontal, PU cuffs showed better leak prevention than PVC cuffs, regardless of shape, whereas the TaperGuard outperformed other, tapered and non-tapered, PVC cuffs. Conversely, in a recent study of intubated pigs (4 pigs per ETT type), Li Bassi et al ${ }^{38}$ found that neither material nor shape affected leak prevention, although leakage was seen with all ETT types. They found that the TaperGuard and SACETT (Smiths Medical, London, United Kingdom), both tapered PVC cuffs, showed the best and worst leak prevention, respectively. It is clear from the bench studies that PU cuffs leak much less than PVC cuffs because the thickness of the cuff reduces the size of the channels when folds develop. The leakage with PU cuffs, although it is greater than with the PneuX, is small, and the clinical impact is unknown. Less clear is the effect of cuff shape on leakage, and no specific advantage can be identified. Further investigation is needed to determine whether a tapered shape does reduce leak and whether cuff material or shape are of any clinical importance.

The leak reduction in our study with PEEP and/or cuff lubrication for HVLP cuffs is consistent with existing literature. The advantage of PEEP/CPAP in reducing leak, offsetting hydrostatic pressure of secretions, has been welldocumented in bench and clinical studies ${ }^{11,13,29}$ and shown to potentially reduce VAP. ${ }^{39}$

The benefit of cuff lubrication is less known, despite being suggested in 1986 by Seegobin and van Hasselt, ${ }^{40}$ the proposed mechanism being gel clogging cuff folds. The efficacy of cuff lubrication has been demonstrated in bench and clinical studies. ${ }^{41,42}$ Dave et $\mathrm{al}^{42}$ observed a $0 \%$ incidence of leakage in 6 different HVLP cuffs with lubrication alone compared with $100 \%$ incidence without lubrication across $60 \mathrm{~min}$ of ventilation in a bench study. In anesthetized subjects intubated with a lubricated cuff, Blunt et $\mathrm{al}^{41}$ found that leak did not occur for $24-120 \mathrm{~h}$ after intubation. Our study reinforces the potential of this low cost, low-effort intervention. Whether this benefit diminishes over time, in certain conditions, or has clinical value in reducing VAP are important considerations for future studies.

\section{Limitations}

All parts of this study were limited by the bench nature and use of simplified tracheal models. Although this ap- proach has been widely used, ${ }^{11,13,21,25,26,28,42}$ the findings require clinical follow-up. In addition, the tracheal model was positioned $90^{\circ}$ from the horizontal, the worst-case scenario for leakage of fluid past the ETT cuff. Although this is not the position most commonly used in the operating room, it is similar to the head-up position used in the ICU and in other bench studies. ${ }^{11,13,21,25,26,28,42}$ Dyed water was placed above the cuff. The lower viscosity of water compared with oral secretions may have resulted in a greater volume of fluid moving past the cuffs. However, all cuffs were evaluated with the same fluid, and the comparisons among cuffs should be the same as if oral secretions were used. There are also specific limitations for each part of this study. In Part 1, fluid leakage in some cuffs occurred despite tracheal wall pressure exceeding the water column height, a phenomenon also encountered by Doyle et al. ${ }^{31}$ In our study, this leakage, probably due to capillary action through cuff folds, appeared as slow, regular dripping through visible channels, distinguishable from the abrupt flow of fluid (flow leakage) through the cuff-wall interface used for tracheal wall pressure calculation. In Part 2, the major limitation was the lack of simulated mechanical ventilation during testing. The aim of this part was only to consider basic functionality, and detailed follow-up is warranted. In Part 3, based on Parts 1 and 2, the PneuX at a seal pressure of $27.2 \mathrm{~cm} \mathrm{H}_{2} \mathrm{O}$ exerts tracheal wall pressure $>30 \mathrm{~cm} \mathrm{H}_{2} \mathrm{O}$, the highest intracuff pressure at which HVLP cuffs were tested, preventing direct comparison of leak prevention ability. However, the settings tested accurately reflect suggested use and what would be encountered clinically. Additionally, our tracheal models were not anatomically accurate. The material and internal surface of the models may have influenced our results. ${ }^{43}$ However, as stated above, this was a worst-case model, and the comparative function across devices we would expect to be qualitatively similar regardless of model, even if quantitative results differed based on model type. However, the efficacy of the model is supported by consistency in the findings from similar bench studies ${ }^{11,13,21,24,26}$ and related

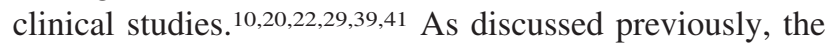
implications of our findings on clinical outcome are unknown. Finally, the ability of the PneuX tracheal wall pressure monitor to avoid excessive tracheal wall pressure requires additional study. We did not focus on the potential of tracheal injury induced by high tracheal wall pressure but simply focused on the prevention of leaks within acceptable tracheal wall pressure ranges.

\section{Conclusions}

The low-volume silicone cuff of the PneuX ETT generally maintains tracheal wall pressure of $20-30 \mathrm{~cm} \mathrm{H}_{2} \mathrm{O}$ when inflated to its recommended intracuff pressure of $80 \mathrm{~cm} \mathrm{H}_{2} \mathrm{O}$, but the tracheal seal monitor maintains intra- 


\section{Performance of Endotracheal Tube Cuffs}

cuff pressure somewhat above this targeted level. In a simple tracheal model, the PneuX prevents leak for $\geq 8 \mathrm{~h}$ at the recommended settings. For HVLP cuffs, PU outperforms PVC, regardless of shape. With all HVLP cuffs, lubrication alone may help prevent leak for $\geq 8 \mathrm{~h}$ at an intracuff pressure of $20-30 \mathrm{~cm} \mathrm{H}_{2} \mathrm{O}$. Additional clinical studies are needed to determine whether these findings actually reflect decreases in aspiration.

\section{REFERENCES}

1. Rello J, Soñora R, Jubert P, Artigas A, Rué M, Vallés J. Pneumonia in intubated patients: role of respiratory airway care. Am J Respir Crit Care Med 1996;154(1):111-115.

2. Kollef MH. The prevention of ventilator-associated pneumonia. N Engl J Med 1999;340(8):627-634.

3. Safdar N, Dezfulian C, Collard HR, Saint S. Clinical and economic consequences of ventilator-associated pneumonia: a systematic review. Crit Care Med 2005;33(10):2184-2193.

4. Restrepo MI, Anzueto A, Arroliga AC, Afessa B, Atkinson MJ, Ho NJ, et al. Economic burden of ventilator-associated pneumonia based on total resource utilization. Infect Control Hosp Epidemiol 2010; 31(5):509-515.

5. Nseir S, Zerimech F, Jaillette E, Artru F, Balduyck M. Microaspiration in intubated critically ill patients: diagnosis and prevention. Infect Disord Drug Targets 2011;11(4):413-423.

6. El-Orbany M, Salem MR. Endotracheal tube cuff leaks: causes, consequences, and management. Anesth Analg 2013;117(2):428-434.

7. Farré R, Rotger M, Ferre M, Torres A, Navajas D. Automatic regulation of the cuff pressure in endotracheally-intubated patients. Eur Respir J 2002;20(4):1010-1013.

8. Valencia M, Ferrer M, Farre R, Navajas D, Badia JR, Nicolas JM, Torres A. Automatic control of tracheal tube cuff pressure in ventilated patients in semirecumbent position: a randomized trial. Crit Care Med 2007;35(6):1543-1549.

9. Chenelle CT, Oto J, Sulemanji D, Fisher DF, Kacmarek RM. Evaluation of an automated endotracheal tube cuff controller during simulated mechanical ventilation. Respir Care 2015;60(2):183-190.

10. Lorente L, Lecuona M, Jiménez A, Mora ML, Sierra A. Influence of an endotracheal tube with polyurethane cuff and subglottic secretion drainage on pneumonia. Am J Respir Crit Care Med 2007;176(11): 1079-1083.

11. Pitts R, Fisher D, Sulemanji D, Kratohvil J, Jiang Y, Kacmarek R. Variables affecting leakage past endotracheal tube cuffs: a bench study. Intensive Care Med 2010;36(12):2066-2073.

12. Ouanes I, Lyazidi A, Danin PE, Rana N, Di Bari A, Abroug F, et al. Mechanical influences on fluid leakage past the tracheal tube cuff in a benchtop model. Intensive Care Med 2011;37(4):695-700.

13. Zanella A, Scaravilli V, Isgrò S, Milan M, Cressoni M, Patroniti N, et al. Fluid leakage across tracheal tube cuff, effect of different cuff material, shape, and positive expiratory pressure: a bench-top study. Intensive Care Med 2011;37(2):343-347.

14. Hamilton VA, Grap MJ. The role of the endotracheal tube cuff in microaspiration. Heart Lung 2012;41(2):167-172.

15. D'Haese J, De Keukeleire T, Remory I, Van Rompaey K, Umbrain V, Poelaert J. Assessment of intraoperative microaspiration: does a modified cuff shape improve sealing? Acta Anaesthesiol Scand 2013; 57(7):873-880.

16. Rouzé A, Nseir S. Continuous control of tracheal cuff pressure for the prevention of ventilator-associated pneumonia in critically ill patients: where is the evidence? Curr Opin Crit Care 2013;19(5):440-447.
17. Young PJ, Rollinson M, Downward G, Henderson S. Leakage of fluid past the tracheal tube cuff in a benchtop model. Br J Anaesth 1997;78(5):557-562.

18. Haas CF, Eakin RM, Konkle MA, Blank R. Endotracheal tubes: old and new. Respir Care 2014;59(6):933-955; discussion 952-955.

19. Dullenkopf A, Gerber A, Weiss M. Fluid leakage past tracheal tube cuffs: Evaluation of the new microcuff endotracheal tube. Intensive Care Med 2003;29(10):1849-1853.

20. Lucangelo U, Zin WA, Antonaglia V, Petrucci L, Viviani M, Buscema G, et al. Effect of positive expiratory pressure and type of tracheal cuff on the incidence of aspiration in mechanically ventilated patients in an intensive care unit. Crit Care Med 2008; 36(2):409-413.

21. Dave MH, Frotzler A, Spielmann N, Madjdpour C, Weiss M. Effect of tracheal tube cuff shape on fluid leakage across the cuff: an in vitro study. Br J Anaesth 2010;105(4):538-543.

22. D'Haese J, De Keukeleire T, Remory I, Van Rompaey K, Umbrain V, Poelaert J. Assessment of intraoperative microaspiration: does a modified cuff shape improve sealing? Acta Anaesthesiol Scand 2013; 57(7):873-880.

23. Young PJ, Ridley SA, Downward G. Evaluation of a new design of tracheal tube cuff to prevent leakage of fluid to the lungs. Br J Anaesth 1998;80(6):796-799.

24. Young PJ, Basson C, Hamilton D, Ridley SA. Prevention of tracheal aspiration using the pressure-limited tracheal tube cuff. Anaesthesia 1999;54(6):559-563.

25. Zanella A, Cressoni M, Epp M, Stylianou M, Kolobow T. A doublelayer tracheal tube cuff designed to prevent leakage: a bench-top study. Intensive Care Med 2008;34(6):1145-1149.

26. Kolobow T, Cressoni M, Epp M, Corti I, Cadringher P, Zanella A. Comparison of a novel lycra endotracheal tube cuff to standard polyvinyl chloride cuff and polyurethane cuff for fluid leak prevention. Respir Care 2011;56(8):1095-1099.

27. Young PJ, Burchett K, Harvey I, Blunt MC. The prevention of pulmonary aspiration with control of tracheal wall pressure using a silicone cuff. Anaesth Intensive Care 2000;28(6):660-665.

28. Young PJ, Young WH. Inflation of a pressure-limited cuff inside a model trachea. Med Eng Phys 2003;25(6):465-473.

29. Young PJ, Pakeerathan S, Blunt MC, Subramanya S. A low-volume, low-pressure tracheal tube cuff reduces pulmonary aspiration. Crit Care Med 2006;34(3):632-639.

30. Fletcher AJ, Ruffell AJ, Young PJ. The LoTrach system: its role in the prevention of ventilator-associated pneumonia. Nurs Crit Care 2008;13(5):260-268.

31. Doyle A, Santhirapala R, Crowe M, Blunt M, Young P. The pressure exerted on the tracheal wall by two endotracheal tube cuffs: a prospective observational bench-top, clinical and radiological study. BMC Anesthesiol 2010;10:21.

32. Doyle A, Fletcher A, Carter J, Blunt M, Young P. The incidence of ventilator-associated pneumonia using the PneuX system with or without elective endotracheal tube exchange: a pilot study. BMC Res Notes 2011;4:92.

33. Inada $T$, Uesugi $F$, Kawachi $S$, Inada $K$. The tracheal tube with a high-volume, low-pressure cuff at various airway inflation pressures. Eur J Anaesthesiol 1998;15(6):629-632.

34. Brimacombe J, Keller C, Giampalmo M, Sparr HJ, Berry A. Direct measurement of mucosal pressures exerted by cuff and non-cuff portions of tracheal tubes with different cuff volumes and head and neck positions. Br J Anaesth 1999;82(5):708-711.

35. Li Bassi G, Ranzani OT, Marti JD, Giunta V, Luque N, Isetta V, et al. An in vitro study to assess determinant features associated with fluid sealing in the design of endotracheal tube cuffs and exerted tracheal pressures. Crit Care Med 2013;41(2):518-526. 


\section{Performance of Endotracheal Tube Cuffs}

36. Weiss M, Doell C, Koepfer N, Madjdpour C, Woitzek K, Bernet V. Rapid pressure compensation by automated cuff pressure controllers worsens sealing in tracheal tubes. Br J Anaesth 2009;102(2):273278.

37. Stewart SL, Seacrest JA, Norwood BR, Zachary R. A comparison of endotracheal tube cuff pressures using estimation techniques and direct intracuff measurement. AANA J 2003;71(6):443-447.

38. Li Bassi G, Luque N, Martí JD, Aguilera Xiol E, Di Pasquale M, Giunta V, et al. Endotracheal tubes for critically ill patients: An in vivo analysis of associated tracheal injury, mucociliary clearance, and sealing efficacy. Chest 2015;147(5):1327-1335.

39. Manzano F, Fernández-Mondéjar E, Colmenero M, Poyatos ME, Rivera R, Machado J, et al. Positive-end expiratory pressure reduces incidence of ventilator-associated pneumonia in nonhypoxemic patients. Crit Care Med 2008;36(8):2225-2231.

40. Seegobin RD, van Hasselt GL. Aspiration beyond endotracheal cuffs. Can Anaesth Soc J 1986;33(3):273-279.

41. Blunt MC, Young PJ, Patil A, Haddock A. Gel lubrication of the tracheal tube cuff reduces pulmonary aspiration. Anesthesiology 2001;95(2):377-381.

42. Dave MH, Koepfer N, Madjdpour C, Frotzler A, Weiss M. Tracheal fluid leakage in benchtop trials: comparison of static versus dynamic ventilation model with and without lubrication. J Anesth 2010;24(2): 247-252.

43. Mehta S, Myat H. The cross-sectional shape and circumference of the human trachea. Ann R Coll Surg Engl 1984;66(5):356-358. 